\title{
The Selective Use of Sound Effects and Visual Inserts for Children's Television Story Comprehension
}

\author{
Sandra L. Calvert \\ Georgetown University \\ Tracey L. Gersh \\ University of North Carolina at Greensboro
}

\begin{abstract}
Sound effects were inserted in a television program in order to guide children's selective attention to, and comprehension of, significant story content. Sixty-four children, equally distributed by sex and by kindergarten and fifth grades, were randomly assigned to one of four treatment conditions that crossed two levels of sound effects with two levels of visual inserts. One-s sound effects either preceded or did not precede three key program transitions. The visual insert conditions provided additional information at these program points whereas the no visual insert conditions did not. Visual attention was videotaped during each child's individual viewing session. After viewing, each child answered a 22 -item multiple-choice recognition test of inferential, central, and incidental content. As predicted, sound effects increased selective attention and inferential recognition, particularty for the youngest children who have the greatest difficulty understanding televised stories.
\end{abstract}

Mature comprehension of a televised story requires that viewers select significant content for processing, temporally integrate that content, and draw inferences about implicit relations among those story events (Collins, Wellman, Keniston, \& Westby, 1978). In view of young children's difficulty in selecting plot-relevant content during viewing (Collins, 1983), one means to improve television story comprehension is to guide visual attention selectively to central content.

Content, per se, does not reliably distinguish plot-relevant from irrelevant information, but certain television production techniques can highlight particular content by eliciting attentional orienting responses from children (Calvert, Hus-

This research was supported by grants from the Home Economics Center for Research, the University of North Carolina at Greensboro Research Council, and the University of North Carolina at Greensboro Summer Faculty Excellence Program. We are grateful to the staff and children of Vandalia Elementary School in the Greensboro School System, and to the children and staff at Vandalia Christian School for participating in this study. We also thank Garrett Lange, Lynette Friedrich Cofer, Robert Nida, Frances Moran, Lynn Hinton, and Paul Whitener for their assistance.

Correspondence and requests for reprints should be sent to Sandra L. Calvert, Department of Psychology, Georgetown University, 37th and O Street, N.W., Washington, DC 20057. 
ton, Watkins, \& Wright, 1982). Orienting responses, in turn, can momentarily enhance information processing activity (Anderson \& Lorch, 1983). This study examines if sound effects, an auditory formal production feature, can serve to guide children's visual attention to story transitions, thereby increasing comprehension.

Inferential reasoning, a key problem in young children's story comprehension, requires viewers to select and integrate program material across different scenes (Collins et al., 1978). Scene changes, in which television programs shift to different times and places, are strategic program points where attentional decisions are made. Young children make fewer attentional discriminations at scene changes than older children (Wright, Calvert, Huston-Stein, \& Watkins, 1980), and they integrate less story content across these changes than older children (Wright et al., 1984). Thus, a first step in enhancing inferential comprehension is to ensure that young children attend during scene changes so that information is available for further processing.

Selective attention to targeted content appears to be more beneficial for comprehension than increases in overall levels of visual attention (Lorch, Anderson, \& Levin, 1979; Pezdek \& Hartman, 1983). For example, Lorch et al. demonstrated that children who watched $44 \%$ versus $87 \%$ of an episode of "Sesame Street" did not differ in comprehension, but comprehension was related to visual attention at specific program points where significant information was presented. However, these studies examined magazine formats that present content in discrete units; magazine formats do not require temporal integration and inferencing of program material.

Selective attention is also associated with comprehension of televised content presented in a story format, but the data base is correlational (Calvert et al., 1982). Production features like sound effects elicit attentional orienting responses from children who are initially inattentive to a program. In addition, sound effects can enhance learning by highlighting certain content, just as a spotlight can focus an audience's attention on a specific actor in a play (Wright \& Huston, 1983). Sound effects that mark important scene changes may increase the probability that children will see and then integrate story content across changes in time and place, thereby improving inferential comprehension.

Visual inserts might also enhance children's comprehension. Palmer and McDowell (1979) inserted program separators to help young children discriminate program material from commercials, but children appeared to use the inserts to bridge, rather than to separate, the story content. If young children do use separators to bridge content transitions, visual inserts may help children link content over time.

With development, children learn to ignore irrelevant content that is incidental to the plot, thereby increasing the relative amount of essential to nonessential content remembered (Collins, 1983). Increases occur in comprehension of central content that is explicitly presented and of inferential content that is implied 
(Collins, Sobol, \& Westby, 1981). Because treatment interventions were targeted at critical plot content, children were expected to learn essential rather than nonessential content, particularly at young ages.

The purpose of this study was to examine if sound effects increase visual attention to, and comprehension of, televised story content about a dream. The story material was presented either with or without visual inserts between story transitions surrounding the dream. A program with a dream sequence was selected for study because older children understand this concept better than younger children (Flavell, 1963). We expected (a) visual attention to increase at targeted program points when sound effects were present rather than absent; (b) central and inferential story comprehension to increase when sound effects were present rather than absent; (c) central and inferential story comprehension to increase when visual inserts were present rather than absent; and (d) incidental comprehension to not be affected by sound effects or visual inserts. Treatment effects were expected to be more pronounced for younger than for older children.

\section{METHOD}

\section{Subjects}

The sample consisted of 64 children who attended a public elementary school in a moderately-sized Southeastern city. Children were equally distributed by sex and by kindergarten ( $M=5$ years, 11 months) and fifth grade ( $M=11$ years, 3 months). Children were randomly assigned within grade and sex groups to one of four treatment conditions.

\section{Television Program}

The television program, "Mama's Little Pirates," was a 14-min black and white, live episode from "The Little Rascals." The program series, designed for children, portrays the adventures of a group of young children and their leader, Spanky. This program was chosen because it was difficult to understand. The story was composed of segments when Spanky was either awake or dreaming. The dream lasted about $9 \mathrm{~min}$.

The story began when Spanky and his friends decided to search for pirate treasure in a dark cave. Spanky returned home for a flashlight. When Spanky's mom found out about the plan, she refused to let him return to the cave and sent him to his room because he would not obey. Spanky climbed into bed and put his head down. A visual special effect created a dream image of Spanky in which he walked out of his body and talked to himself about going to the cave. After his reverie, his dream-self walked back into his body. The scene then shifted from his bedroom to the cave where he and his friends searched for treasure. Although not apparent, this search was part of the dream. The children found a large treasure chest, but then they got lost and found themselves in a giant's house. The giant chased them for stealing his treasure. While Spanky was running, he 
remembered his mother's warnings. Spanky then awakened in his bed and fell on the floor. His friends were at the window asking him to go back to the cave.

\section{Design and Treatment Conditions}

In all four treatment conditions, the program plot was retained. The four experimental conditions were (a) no sound effects and no visual inserts; (b) sound effects and no visual inserts; (c) no sound effects and visual inserts; and (d) sound effects and visual inserts. One-s sound effects were presented immediately before three transitional story points. The sound effects made a whistling noise that popped as they ended. By editing the program, visual inserts varied whether or not Spanky was shown asleep in his bed at the same three story points. Program lengths were $13 \mathrm{~min} 12 \mathrm{~s}$ in no insert conditions and $13 \mathrm{~min} 47 \mathrm{~s}$ in visual insert conditions.

\section{Procedure}

Children were tested individually in a vacant classroom at school. Each child was seated beside an experimenter at a table. Small toys and comic books were available for play. The child was told to play and watch television just like at home and that some questions about the story would be asked after the program ended. With remote control buttons, the experimenter activated a hidden camera which videotaped the viewing session and a videotape recorder which played one of the four edited program versions. These procedures were adapted from ones which had been previously developed (cf. Calvert et al., 1982).

\section{Visual Attention}

Each child's visual orientation to the television screen was scored from videotapes.

Duration of Visual Attention. Overall durations of visual attention were scored by turning a stopwatch on when a child looked at the television screen and off when a child looked away. Attention was scored for two program segments: before the onset of any treatments $(3 \mathrm{~min} 56 \mathrm{~s}$ ) and after the onset of treatments ( 9 min $16 \mathrm{~s}$ for no insert conditions and $9 \mathrm{~min} 56 \mathrm{~s}$ for visual insert conditions).

Interobserver agreement, based on eight randomly selected viewing sessions, was $94 \%$ using the formula of $2 \times$ the number of seconds the observers agreed that children were looking at the television screen divided by the total number of seconds of visual attention scored by both observers. To correct for differential program lengths, all scores were converted to the percent of visual attention before and after treatments.

Recruit Attention Scores. To measure recruit attention scores, a scorer first examined whether or not the child was looking at the television screen at the three program transitions. If the child was not looking, the scorer determined if 
the child looked back at the television screen within $5 \mathrm{~s}$ after the sound effect occurred or during that same time frame in the no sound effect conditions. If a child reoriented attention to the television screen within that 5-s frame, the child was scored as recruited.

Interobserver agreement, based on 10 randomly selected viewing sessions, was $97 \%$ using the formula $2 \times$ the number of agreements divided by the total number of scores for both observers. Agreement occurred when both observers scored an onset or offset of attention within $5 \mathrm{~s}$ after the sound effect occurred or during that same program time frame for no sound effect conditions. Recruit scores were converted to percentages.

\section{Comprehension: Multiple-Choice Recognition Scores}

After viewing, each child answered three types of multiple-choice comprehension questions: inferential, central, and incidental. The rationale and method for creating these categories came from a well-established research line (e.g., Collins, 1970, 1983; Collins et al., 1978). Initially, children's retention of only central (plot-essential) and incidental (nonessential) content was examined (Collins, 1970). Central content was later divided into story content that is explicitly or implicitly presented (e.g., Collins et al., 1981; Collins et al., 1978). Processing implicitly presented content is more difficult than processing explicitly presented content because implicit comprehension requires a viewer to make inferences, a major deficiency in children's processing of televised stories. In the present study, implicit content was given the name "inferential" whereas explicit content retained the name "central."

Ratings by adult judges have been a standard method for developing measures of central, inferential, or incidental content (e.g., Calvert et al., 1982; Collins, 1970). Following procedures adapted from Collins (1983), two adults who were familiar with the program identified central and incidental story events and placed those events in an open-ended questionnaire. Central content was defined as plot-essential information whereas incidental content was defined as information that was peripheral to the plot. This questionnaire was completed by 42 adults who viewed the program, rated each question as central or incidental to the plot, and answered each question. Items with a minimum centrality rating of $80 \%$ were retained. Central questions were classified as either explicitly presented facts or as inferences requiring temporal integration of content and an understanding of character feelings and motives. Incidental questions contained humorous or irrelevant content.

To construct multiple-choice alternatives, three verbal responses were taken from the questionnaires. Each question was presented with a relevant photograph from the program. There were 7 inferential items, 5 central items, and 10 incidental items. An example of an inferential item was "What lesson does Spanky learn? A) To listen to his mom; B) To listen to himself; or C) Not to dump cereal in his dad's bowl." A central item was "Why does Spanky's mom 
tell him not to go into the cave? A) Because it was too dark; B) Because it was dangerous; or C) Because a giant lived there." An incidental item was "How did Spanky leave the breakfast table? A) By sneaking out behind his mother; B) By saying 'Excuse me'; or C) By crawling under the table."

Each child answered this 22 -item multiple-choice recognition measure which consisted of a picture, a question, and three response options. The multiplechoice test measured recognition of program content while controlling for possible age differences in verbal ability. Items were arranged randomly within a book. The experimenter read each question aloud, pointing to alternatives that were color-coded as a red " $A$," a blue " $B$," or a green " $C$." The child pointed to a response option and turned the pages of the book as the experimenter circled the child's response choices on an answer sheet. Each session lasted approximately $45 \mathrm{~min}$.

\section{RESULTS}

\section{Multiple-Choice Recognition Scores}

The correct number of inferential, central, and incidental responses were submitted to a 2 (sound effect) $\times 2$ (visual insert) $\times 2$ (grade) $\times 2$ (sex) multivariate analysis of variance. Significant multivariate effects (Wilks Lambda) were obtained for sound effect with grade, $F(3,46)=4.38, p<.01$; for visual insert with grade, $F(3,46)=3.60, p<.05$; for sound effect with $\operatorname{sex}, F(3,46)=5.24$, $p<.01$; and for grade, $F(3,46)=30.13, p<.001$.

In order to interpret the multivariate effects, 2 (sound effect) $\times 2$ (visual insert) $\times 2$ (grade) $\times 2$ (sex) univariate analyses of variance were computed on inferential, central, and incidental scores. Duncan's multiple-range tests, $p$ $<.05$, were used to identify significant differences among means.

As seen in Table 1, the multivariate sound effect with grade interaction was due to differences between kindergartners' and fifth graders' inferential recognition in sound effect versus no sound effect conditions, univariate $F(1,48)=$ $5.14, p<.05$. Duncan's multiple range test revealed that kindergartners recog-

TABLE 1

Developmental Differences in Mean Number of Inferential Items Correct as a Function of Sound Effect Treatment

\begin{tabular}{|c|c|c|c|c|}
\hline \multirow[b]{2}{*}{ Treatment } & \multicolumn{2}{|c|}{$\begin{array}{c}\text { Kindergarten } \\
\qquad(N=32)\end{array}$} & \multicolumn{2}{|c|}{$\begin{array}{c}\text { Fifth } \\
(N=32)\end{array}$} \\
\hline & $M$ & $S D$ & $\boldsymbol{M}$ & $S D$ \\
\hline No sound effect & $2.00^{c}$ & 1.37 & $5.75^{\mathrm{a}}$ & 1.06 \\
\hline Sound effect & $3.38^{b}$ & 1.45 & $5.69^{a}$ & 1.25 \\
\hline
\end{tabular}

Note. Means with different letter superscripts are significantly different at $p<.05$. 
nized more inferential content under the sound effect conditions, but fifth grade performance was comparable in the sound effect and no sound effect conditions. Kindergartners who did not hear sound effects responded at chance level on inferential items.

The multivariate grade with visual insert interaction was due to differences in kindergartners' and fifth graders' inferential recognition in visual insert versus no visual insert conditions, $F(1,48)=5.14, p<.05$. Duncan's multiple range test revealed that kindergartners recognized inferential content better without $(M=$ $3.25 ; S D=1.53)$ than with visual inserts $(M=2.13 ; S D=1.41)$ whereas fifth grade performance was comparable without $(M=5.76 ; S D=1.36)$ and with visual inserts $(M=5.88 ; S D=.89)$.

The multivariate sex with sound effect interaction was due to differences in central recognition for boys and girls in no sound effect versus sound effect treatment conditions, univariate $F(1,48)=5.79, p<.05$. As seen in Table 2 , Duncan's multiple range test, $p<.05$, revealed that boys and girls in sound effect conditions did not differ from other conditions in central recognition, but boys in no sound effect conditions recognized significantly more central content than did girls in no sound effect conditions.

The multivariate grade effect occurred because fifth graders performed better than did kindergartners on inferential, univariate $F(1,48)=91.35, p<.001$ (5.72 vs. 2.69 ); central, univariate $F(1,48)=31.50, p<.001$ (4.53 vs. 3.22 ); and incidental recognition, univariate $F(1,48)=12.80, p<.001$ (6.50 vs. 5.06).

In order to examine the relation of the three comprehension categories, correlations were computed among inferential, central, and incidental scores at each age level. Comprehension scores were moderately correlated, ranging from .10 to .30 , but none were significant. ${ }^{1}$

\section{Duration of Attention Scores}

Sound effects might influence comprehension because overall durations of visual attention increased due to treatments or were different before treatments even began. To test this hypothesis, a 2 (sound effect) $\times 2$ (visual insert) $\times 2$ (grade) $\times 2$ (sex) between-subjects analysis of variance was run on percentages of visual attention before and after treatment onset.

No changes in overall levels of visual attention occurred before or after treatments. Before treatments main effects occurred for both grade, $F(1,48)=$ $37.75, p<.001$; and sex, $F(1,48)=8.53, p<.01$. After the onset of treatments, main effects again occurred for grade, $F(1,48)=56.11, p<.001$; and sex, $F(1,48)=9.40, p<.01$. Fifth graders viewed more of the program than

\footnotetext{
1Specific correlations among the three comprehension categories can be obtained from the first author upon request.
} 
TABLE 2

Sex Differences in Mean Number of Central Items Correct as a Function of Sound Effect Treatment

\begin{tabular}{llllll}
\hline & \multicolumn{2}{c}{$\begin{array}{c}\text { No Sound Effect } \\
(N=32)\end{array}$} & & \multicolumn{2}{c}{$\begin{array}{c}\text { Sound Effect } \\
(N=32)\end{array}$} \\
\cline { 2 - 6 } Sex & $M$ & $S D$ & & & $S D$ \\
\hline Boys & $4.25^{\mathrm{a}}$ & 1.06 & & 3.75 & 1.13 \\
Girls & $3.44^{\mathrm{b}}$ & 1.21 & 4.06 & 1.18 \\
\hline
\end{tabular}

Note. Means with different letter superscripts are significantly different at $p<.05$.

did kindergartners before ( $81 \%$ vs. $46 \%$, respectively) and after ( $81 \%$ vs. $45 \%)$ treatment onset. Girls viewed more of the program than did boys before (72\% vs. $55 \%$, respectively) and after (70\% vs. $56 \%)$ treatment onset.

\section{Recruit Attention Scores}

We expected that sound effects might improve comprehension because attention was enhanced during program transitions, thereby helping children to integrate content across scenes. Recruit scores were computed to compare visual attention immediately before and immediately after the three transitional story points. Change scores in visual attention were collapsed across the sound effects. Pearson correlations were computed between sound effect treatments and recruit attention scores as a function of grade and sex. Correlations were two-tailed with 16 degrees of freedom.

As expected, kindergartners were significantly more likely to look back at the television screen when sound effects were present rather than absent. The correlation between sound effect treatment and recruit attention scores was significant for both younger boys, $r=.83, p<.001$; and younger girls, $r=.69, p$ $<.01$.

Because fifth graders were typically attending at these three program points, there was not a significant relation between sound effect treatment and recruit attention scores. Nevertheless, the recruiting scores were positively related to sound effect treatments for both older boys and older girls.

\section{Relation between Attention and Comprehension}

The final analysis compared overall levels of visual attention against attention to specific program points in relation to comprehension of content. Pearson-product moment correlations were computed between recruit attention scores, duration of attention scores before the onset of treatments, and duration of attention scores after the onset of treatments with recognition of inferential, central, and incidental content. Because age and sex differences occurred on several measures, correlations are reported as a function of grade and sex. Correlations are twotailed with 16 degrees of freedom. 
We expected a positive correlation between kindergartners' recruit attention scores and their inferential recognition. As seen in Table 3, kindergartners' recruit attention scores were positively correlated with inferential recognition, but this effect was present only for young boys, $p=.06$. Young boys' duration of attention after treatment onset was also significantly related to inferential recognition. There were no other significant relations between attention and inferential recognition, but there was a trend between older boys' duration of attention before the onset of treatment and their inferential comprehension, $p$ $=.07$. Recognition of central content also was related to older boys' duration of attention before the onset of treatment. There were no other significant relations between attention and recognition of central content.

The most consistent relations between attention and comprehension were between duration of attention scores and comprehension of incidental content. Significant correlations were present between duration of attention before treatment onset and recognition of incidental content for younger boys, younger girls, and older boys. Duration of attention after treatment onset was related to incidental recognition for younger girls.

In summary, young boys' comprehension of significant story content benefited most from attention to sound effects. Overall durations of attention, especially before the onset of treatment, often were related to children's comprehension of irrelevant, incidental content. Older boys demonstrated the clearest skills at attending selectively to all types of content without any treatment interventions. Older girls showed no relation between attention and comprehension scores, perhaps because they looked so much at the program that there was little variance within the group.

\section{DISCUSSION}

A major finding of this study is that young children can use sound effects to guide their selective attention to significant television story content. Collins et al. (1978) reported that second graders failed to infer interscene connections across program transitions. By highlighting three important story transitions with sound effects, kindergartners' attention was recruited and their inferential comprehension increased. Even if sound effects initially produce an involuntary attentional orienting response (Anderson \& Lorch, 1983; Ohman, 1979), increases in inferential comprehension suggest that children can use sound effects as a cue that something important is coming.

The correlations between attention and inferential comprehension suggest that young boys benefit from sound effects more so than young girls. Calvert and Scott (1986) also reported that young boys are more attentive than are young girls after hearing sound effects. Because sound effects are often paired with content that is directed at boys (Welch, Huston-Stein, Wright, \& Plehal, 1979), they may be learning at young ages that content which follows sound effects is 


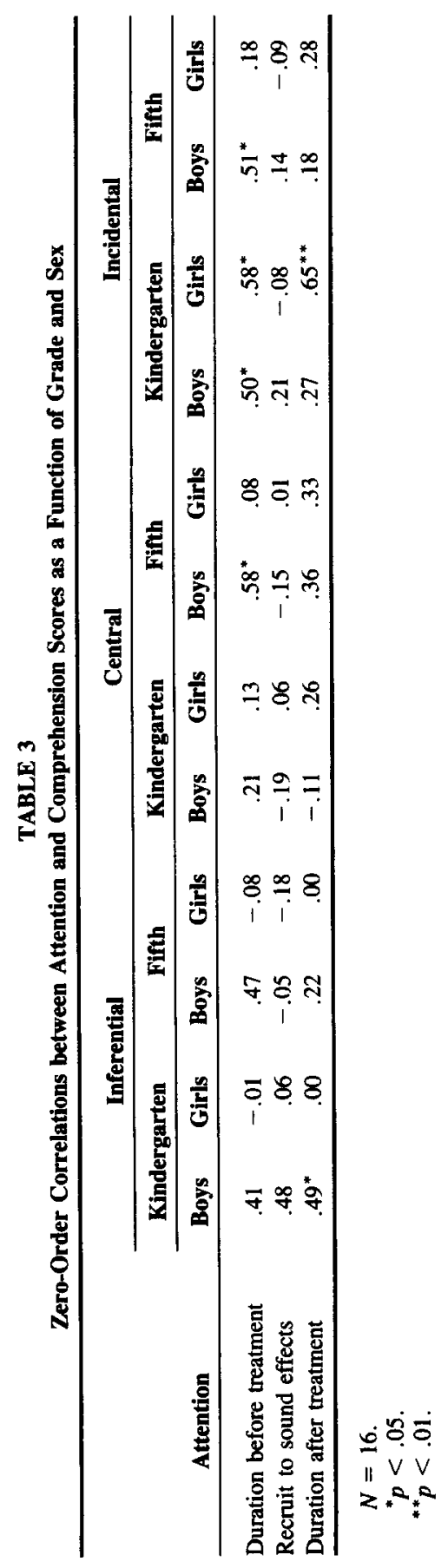


intended for them. Alternately, boys may have found the content they saw after hearing sound effects more interesting than did the girls.

Because there was a trend between fifth grade boys' inferential comprehension and overall durations of visual attention before any treatments occurred, they did not need sound effects to guide their attention to essential program content as much as the younger children did. Collins et al. (1978) reported that by the fifth grade, children understood inferential content from an adult television program. Taken together, the findings suggest that attentional strategies mature by late childhood. Nevertheless, older children may benefit if sound effects or swelling music are placed selectively in adult programs that are difficult for them to understand, or if the comprehension task is more challenging than a recognition measure.

When sound effects were present, girls understood central content just as well as boys, but when there were no sound effects boys understood central content better than girls. The sex difference in central recognition reported here is striking given that overall levels of attention to the program by girls were higher than those of boys. However, older boys' duration of attention prior to treatment was related to their comprehension of central content whereas older girls' attention was not related. The results suggest that sound effects can highlight central content for those children who need it.

Duration of attention was related to recognition of irrelevant, incidental content at both grades. Calvert, Huston, and Wright (1987) reported a significant relation between children's durations of visual attention and their incidental story comprehension. "Sesame Street" pairs attention-getting production techniques with important content (Bryant, Zillmann, \& Brown, 1983), thus, perhaps increases in overall attention did not affect comprehension (Lorch et al., 1979; Pezdek \& Hartman, 1983) because only comprehension of important content was tested. In fact, "Sesame Street" may teach young children that formal features like sound effects can serve as markers of important content.

Although comprehension of all content types increased linearly with grade, sound effects affected the relative amount of essential (inferential and central) to nonessential (incidental) content remembered by young children and girls. That is, sound effects increased comprehension of essential over nonessential content. Five-year-old children who heard sound effects better understood difficult content about dreaming, a concept that is usually not understood until age 10 (Flavell, 1963). The results suggest that sound effects can enhance learning of significant television content.

Contrary to expectation, visual inserts disrupted kindergartners' inferential comprehension. The best interpretation of this finding seems to be that technical restrictions prevented the inclusion of inserts that were identical with original program style. Rather than bridging transitions, the artificial quality of the inserts appeared to be confusing. Visual inserts might work in a different television program, especially if greater control of the content within the inserts is possible 
and if the inserts are of comparable production quality to the original broadcast material.

The use of only one television program limits the generality of the findings. The age and sex differences reported in this study should be examined across a range of television content. Perhaps the sex differences were partly due to boys' greater interest in the program plot or in the predominantly male cast of characters. Future research should extend the data base about sound effects by examining their use in nonstereotypical programs, animated versus live programs, rapidly versus slowly paced programs, and programs with "flashbacks" where distortions of time and place occur.

In conclusion, young children's comprehension of plot-essential content can benefit if attention is guided selectively by sound effects. The way a program is constructed may well affect how young children understand the content. The production cost of sound effects is minimal, yet their beneficial effects on comprehension seem promising. Young children can be assisted in active processing and understanding of televised stories if producers of children's television programs mark key program transitions and important story points with sound effects.

\section{REFERENCES}

Anderson, D.R., \& Lorch, E.P. (1983). Looking at television: Action or reaction? In J. Bryant \& D.R. Anderson (Eds.), Children's understanding of television: Research on attention and comprehension (pp. 1-33). New York: Academic.

Bryant, J., Zillmann, D., \& Brown, D. (1983). Entertainment features in children's educational television: Effects on attention and information acquisition. In J. Bryant \& D.R. Anderson (Eds.), Children's understanding of television: Research on attention and comprehension (pp. 221-238). New York: Academic.

Calvert, S.L., Huston, A.C., Watkins, B.A., \& Wright, J.C. (1982). The relation between selective attention to television forms and children's comprehension of content. Child Development, $53,601-610$.

Calvert, S.L., Huston, A.C., \& Wright, J.C. (1987). Effects of television preplay formats on children's attention and story comprehension. Journal of Applied Developmental Psychology, 8, 329-392.

Calvert, S.L., \& Scott, M.C. (1986, August). Production feature effects on children's comprehension of time. Poster session presented at the annual meeting of the American Psychological Association, Washington, DC.

Collins, W.A. (1970). Learning of media content: A developmental study. Child Development, 41, $1133-1142$.

Collins, W.A. (1983). Interpretation and inference in children's television viewing. In J. Bryant \& D.R. Anderson (Eds.), Children's understanding of television: Research on attention and comprehension (pp. 125-150). New York: Academic.

Collins, W.A., Sobol, B.L., \& Westby, S. (1981). Effects of adult commentary on children's comprehension and inferences about a televised aggressive portrayal. Child Development, 52. $158-163$.

Collins, W.A., Wellman, H., Keniston, A.H., \& Westby, S.D. (1978). Age-related aspects of comprehension and inference from a televised dramatic narrative. Child Development, 49, 389-399. 
Flavell, J. (1963). The developmental psychology of Jean Piaget. New York: Van Nostrand.

Lorch, E.P., Anderson, D.R., \& Levin, S.R. (1979). The relationship of visual attention and children's comprehension of television. Child Development, 26(2), 126-135.

Ohman, A. (1979). The orienting response, attention, and learning: An information processing perspective. In H.D. Kimmel, E.H. van Olst, \& J.F. Orlebeke (Eds.), The orienting reflex in humans. Hillsdale, NJ: Erlbaum.

Palmer, E.L., \& McDowell, C.N. (1979). Program/commercial separators in children's television programming. Journal of Communication, 29, 197-201.

Pezdek, K., \& Hartman, E. (1983). Children's television viewing: Attention and comprehension of auditory versus visual information. Child Development, 54, 1015-1023.

Welch, R., Huston-Stein, A., Wright, J.C., \& Plehal, R. (1979). Subtle sex-role cues in children's commercials. Journal of Communication, 29, 202-209.

Wright, J.C., Calvert, S.L., Huston-Stein, A.C., \& Watkins, B.A. (1980, May). Children's selective attention to television forms: Effects of salient and informative production features as functions of age and viewing experience. Paper presented at the annual meeting of the International Communication Association, Acapulco, Mexico.

Wright, J.C., \& Huston, A.C. (1983). A matter of form: Potentials of television for young viewers. American Psychologist, 35, 835-843.

Wright, J.C., Huston, A.C., Ross, R.P., Calvert, S.L., Rolandelli, D., Weeks, L.A., Raessi, P., \& Potts, R. (1984). Pace and continuity of television programs: Effects on children's attention and comprehension. Developmental Psychology, 20, 653-666. 